\title{
O DIREITO DA ANTIDISCRIMINAÇÃO E A TENSÃO ENTRE O DIREITO À DIFERENÇA E O DIREITO GERAL DE IGUALDADE
}

\author{
ROGER RAUPP RIOS ${ }^{1}$
}

\begin{abstract}
RESUMO: O enfrentamento das discriminações constitucionalmente censuradas requer a compreensão e a construção de um campo próprio à reflexão e à prática jurídicas, denominado "direito da antidiscriminação". No seu interior, um dos debates mais acirrados e fundamentais diz respeito às exigências do direito de igualdade, consubstanciado entre a afirmação de um direito à diferença e a proclamação de um direito geral de igualdade. Daí as discussões sobre a natureza e a adequação das medidas necessárias para a consecução deste objetivo. Essas medidas devem ser universalistas ou particularistas? É necessário e politicamente desejável, do ponto de vista da construção de uma sociedade mais justa, conforme os imperativos de igualdade, liberdade e combate à discriminação, a existência de legislação de proteção específica para cada grupo discriminado? Ou é preferível uma legislação universalista, desenhada de forma abstrata, com o objetivo de combater todo e qualquer tipo de discriminação? Propõe-se uma compreensão do direito de igualdade e de seu mandamento antidiscriminatório que supere tais dilemas, mediante a afirmação de um igualitarismo concreto.

PALAVRAS-CHAVE: Direitos Fundamentais; Direito da Antidiscriminação;
\end{abstract} Direito à Diferença; Direito à Igualdade.

ABSTRACT: Facing constitutionally censored discriminations requires the understanding and construction of a proper field of reflection and practice of the law, called the "anti-discrimination law." Within it, one of the fiercest and fundamental debate concerns the requirements of the right to equality, embodied between the affirmation of a right to difference and the proclamation of a general right to equality. That is why, the debates about the nature and adequacy of the necessary means to achieve this goal. Those means should be universal or particularistic? The existence of specific protective legislations to each discriminated group, is politically necessary and desirable from the standpoint of the construction of a fairer society, according to the imperatives of equality, freedom and the struggle against discrimination? Or it is preferable a universalistic rule, designed in an abstract way, in order to struggle any kind of discrimination? It is proposed an understanding of the right to equality and of its

Artigo recebido em 22.08.2011. Pareceres emitidos em 27.10.2011 e 03.02.2012.

Artigo aceito para publicação em 12.03.2012.

${ }^{1}$ Doutor em Direito pela Universidade Federal do Rio Grande do Sul - UFRGS, RS, Professor do Mestrado em Direitos Humanos do Centro Universitário Ritter dos Reis - UniRitter, RS roger.raupp.rios@gmail.com 
anti-discriminatory order that overcomes those dilemmas, by stating a specific and concrete egalitarianism.

KEY-WORDS: Fundamental Rights; Anti-discrimination Law; Right to Difference; Right to Equality.

SUMÁRIO: Introdução; 1 Entre a Distribuição e o Reconhecimento: universalismo ou particularismo?; 2 Direito à Igualdade ou Direito à Diferença?; 3 Proteger Discriminando ou Discriminar Protegendo?; Referências.

SUMMARY: Introduction; 1 Between Distribution and Recognition: universalism and particularism?; 2 Right to Difference or a General Right to Equality?; 3 To Protect Discriminating or to Discriminate Protecting?; References.

\section{INTRODUÇÃO}

Assim como no campo das ciências sociais, um dos debates contemporâneos mais acirrados no mundo jurídico diz respeito ao conteúdo e às exigências normativas da igualdade entendida como direito humano e constitucional. Em tal contexto, a polêmica entre a afirmação de um direito à diferença e a proclamação de um direito geral de igualdade se apresenta de forma direta. Pululam reivindicações pelo reconhecimento legislativo e judicial de direitos de diversos grupos e indivíduos, vinculados a referenciais identitários ou a determinadas situações concretas.

Nessa linha, estabelecem-se discussões sobre a natureza e a adequação das medidas possíveis. Elas devem ser universalistas ou particularistas? É necessária e politicamente desejável, do ponto de vista da construção de uma sociedade mais justa, conforme os imperativos de igualdade, liberdade e combate à discriminação, a existência de legislação de proteção específica para cada grupo discriminado? Ou é preferível uma legislação universalista, desenhada de forma abstrata, com o objetivo de combater todo e qualquer tipo de discriminação? Do ponto de vista jurídico, tais questões indagam as respostas jurídicas diante do fenômeno discriminatório, ensejando a compreensão e a construção de um campo próprio à reflexão e à prática jurídicas, a que se pode chamar de "direito da antidiscriminação" (Rios, 2008).

Diante desse desafio, esta reflexão se divide em três partes. Na primeira, valho-me do esquema proposto por Nancy Fraser $(1997,2001)$, segundo o qual os paradigmas de distribuição e reconhecimento possibilitam a compreensão adequada das questões de justiça trazidas pelas chamadas políticas identitárias no mundo atual; na segunda, examino a tensão entre as reivindicações de um direito à igualdade e as de um direito à diferença; na terceira, vislumbro o dilema que desafia as respostas suscitadas pelas realidades discriminatórias.

1 ENTRE A DISTRIBUIÇÃO E O RECONHECIMENTO: UNIVERSALISMO OU PARTICULARISMO?

Segundo Nancy Fraser, as atuais compreensões sobre justiça podem ser esquematizadas com base nos paradigmas da justiça socioeconômica e da justiça cultural ou simbólica: distribuição e reconhecimento, respectivamente 
(Fraser, 1997: 13-6). No paradigma da distribuição, a injustiça se relaciona com a estrutura econômica da sociedade, preocupando-se com situações de exploração (apropriação do trabalho alheio em benefício de outros); marginalização (confinamento a situações de baixa remuneração e impossibilidade de melhores condições) e privação de condições de vida materialmente adequadas. No paradigma do reconhecimento, refere-se a padrões sociais de representação, interpretação e comunicação, exemplificados por situações de dominação cultural (sujeitar-se a padrões de interpretação e de comunicação próprios de outra cultura, alheios e hostis à cultura do grupo dominado); não-reconhecimento (práticas culturais dominantes que tornam invisíveis e irrelevantes determinados grupos) e desrespeito (ser cotidianamente injuriado ou menosprezado por meio de estereótipos presentes na cultura dominante e nas interações sociais).

Dessa caracterização ${ }^{2}$ decorrem os respectivos remédios para tais tipos de injustiça, cuja relação com as questões do direito da antidiscriminação é direta: enquanto a injustiça econômica, ao reclamar a redistribuição dos bens materiais, aponta para esquemas igualitários e universalistas, a injustiça cultural ou simbólica exige o reconhecimento dos grupos estigmatizados numa dinâmica diferenciadora e particularista. Eis o dilema entre reconhecimento e distribuição: ao passo que a primeira demanda se inclina a produzir diferenciação e particularismo, a segunda tende a enfraquecê-los; medidas redistributivas propõem esquemas universalistas e igualitários; políticas de reconhecimento têm a propensão de condená-los.

É importante assinalar que o esquema proposto não ignora, nem refuta a imbricação entre reconhecimento e distribuição como medidas necessárias à superação da injustiça; antes disso, porém, busca chamar a atenção para ambas as perspectivas, possibilitando inclusive a pesquisa de quais são as interações de uma espécie de medida sobre a outra e até que ponto medidas concretas, considerados os dois pontos de vista, auxiliam ou prejudicam a superação de injustiças.

Nesse mesmo sentido, Fraser salienta a necessidade de conciliar tais preocupações, sob pena de fracasso no combate à injustiça. Em suas palavras:

Essa distinção entre remédios redistributivos e remédios de reconhecimento é analítica. Remédios redistributivos geralmente pressupõem uma concepção de reconhecimento subjacente. Por exemplo, alguns proponentes de redistribuição socioeconômica igualitária fundam suas reivindicações no "igual valor das pessoas"; assim, eles consideram redistribuição econômica uma expressão de reconhecimento. Diversamente, remédios de reconhecimento algumas

\footnotetext{
${ }^{2} \mathrm{Na}$ perspectiva predominantemente distributivista, encontram-se autores como John Rawls e Ronald Dworkin; na perspectiva em que o reconhecimento prevalece, Charles Taylor e Axel Honneth.
} 
vezes pressupõem uma concepção de redistribuição subjacente. Por exemplo, alguns proponentes do reconhecimento multicultural fundamentam suas reivindicações em imperativos de uma justa distribuição dos 'bens primários' de uma 'estrutura cultural intacta'; eles, portanto, consideram reconhecimento cultural uma espécie de redistribuição (Fraser, 2001: 15-6).

Para a compreensão e o desenvolvimento do direito da antidiscriminação esses paradigmas são muito valiosos. A todo instante, a luta por direitos protagonizada por grupos discriminados se depara com tais tensões, como revelam os remédios que vão do combate à discriminação direta, intencional e explícita até a adoção de medidas diferenciadas positivas, sejam estas no sentido da acomodação das diferenças ou de ações afirmativas. A própria enumeração de critérios proibidos de discriminação pode ser compreendida como um reforço do mandamento constitucional de igualdade formal (objetivando instituir efetiva indiferença diante dos particularismos individuais ou grupais) ou como reconhecimento das diversas identidades sob as quais se organizam os grupos sociais que compõem a coletividade.

No debate jurídico, essas tensões serão traduzidas, por exemplo, na dissonância argumentativa entre os partidários da neutralidade e de um método procedimental na interpretação constitucional e os adeptos de uma interpretação informada por certos conteúdos substantivos; na discussão jurisprudencial acerca da censura constitucional diante de discriminação indireta, especialmente quando se denunciam os resultados perversos de uma aplicação formalmente neutra de critérios com impactos diferenciados na realidade; e na polêmica a respeito da constitucionalidade das ações afirmativas, quando se questiona a utilização de critérios proibidos de discriminação como instrumento de superação de realidades discriminatórias.

\section{DIREITO À IGUALDADE OU DIREITO À DIFERENÇA?}

No fundo, a tensão entre os paradigmas da distribuição e do reconhecimento traz à tona a tensão entre as formulações de um direito geral de igualdade e as do direito à diferença. Desde a Revolução Francesa, o projeto político de abolir os privilégios e superar a sociedade estamental se associou à formulação da igualdade jurídica como componente essencial do Estado de Direito e da democracia, considerando-se a defesa da diferença uma estratégia conservadora e retrógrada. Todavia, como indicado acima, nas últimas décadas do século $x x$, grupos e movimentos sociais que reivindicam agendas progressistas passaram a perseguir o reconhecimento das diferenças e a promoção da diversidade.

A postulação de um "direito à diferença" nesse contexto irrompeu da crítica a um universalismo político e jurídico que, sob o pretexto de destruir as antigas hierarquias, corre o risco de atuar de modo formalista, criando e reforçando antigas e novas desigualdades e discriminações. Fruto da assunção de um paradigma pretensamente universal, essa igualdade formal 
se corrompe ao eleger como parâmetro pressuposto um sujeito social nada abstrato: masculino, branco, europeu, cristão, heterossexual, burguês e proprietário.

Duas possíveis compreensões dos critérios proibidos de discriminação, também percebidas nas respostas jurídicas às diversas situações de discriminação, desde a criminalização da discriminação explícita e intencional até as ações afirmativas, decorrem dessa tensão. Com efeito, na enumeração das proibições de discriminação, estas podem ser entendidas como desdobramentos da igualdade formal ou como reconhecimento da diversidade e do dever de sua promoção. A tais compreensões podem ser associados também os "diferencialismos" contemporâneos (Pierucci, 1999).

O "diferencialismo de direita" insiste na afirmação das diferenças como estratégia antiigualitarista, a fim de justificar xenofobia, racismo e chauvinismo, entre outras heterofobias (a chamada "direita identitária"), na tradição contra-revolucionária francesa. Já o "diferencialismo de esquerda" conclama o "direito à diferença" sob a convicção do valor, do respeito e da peculiaridade das diferenças, ${ }^{3}$ cabendo-Ihe tarefa mais árdua: abraçar a diferença, sem abrir mão da igualdade. ${ }^{4}$

Esses dois diferencialismos comungam, como o próprio termo revela, numa desconfiança em face da idéia de um ser humano abstrato, sujeito de direito universalizado. Do ponto de vista da promoção da igualdade, tal postura é bastante discutida, por arriscar-se a tonificar o discurso conservador, haja vista acentuar uma de suas vertentes mais tradicionais e recorrentes na contemporaneidade. Além dos já citados exemplos do racismo e do chauvinismo, esse perigo também pode ser exemplificado na esfera da sexualidade. Abordagens médicas, hoje reforçadas pelo fascínio da genética (Stein, 1999), podem ser utilizadas para justificar regimes diferenciados para gays e lésbicas, e inclusive "terapias curativas". Diferenças biológicas também legitimariam tratamentos e acesso diferenciados a diversos bens relacionados à sexualidade.

Uma alternativa a esse dilema seria defender um "diferencialismo radical", ou seja, levar às últimas conseqüências o processo de diferenciação que produz o reconhecimento de uma identidade coletivamente compartilhada.

\footnotetext{
${ }^{3}$ Essa dinâmica foi assinalada por Charles Taylor como o movimento da ideia de dignidade humana em direção à política das diferenças (Taylor, 1995: 25, 37-44).

4 "Defender a diferença não quer dizer defender a hierarquização, me dizem, te dizem, sem se darem conta de que a 'igualdade na diferença' não passa de um wishful thinking de esquerda, uma prescrição ilusória, uma tentação de onipotência nominalista, porquanto em choque frontal com o axioma linguístico neokantiano - inescapável - segundo o qual não se pode afirmar uma diferença sem afirmar ao mesmo tempo uma diferença de valor. [...] O antropólogo francês Louis Dumont chegou a trabalhar esta impossibilidade, a impossibilidade de desimplicar uma da outra a diferença e a hierarquia: nos quadros culturais de qualquer sociedade humana, sejam as sociedades tradicionais holísticas, sejam as sociedades modernas individualistas, não existe diferença cultural que não se interprete ao mesmo tempo como diferença de valor, portanto, como hierarquia, explícita ou implícita" (Pierucci, 1999: 32-3, grifos adicionados).
} 
Dito de outro modo, até o ponto em que a fragmentação das múltiplas identidades possíveis em cada grupo desemboca numa nova espécie de universalismo, fruto da condição ímpar de cada sujeito, que é resultado dessa característica disseminante, dessa espiral da diferenciação ínsita à perspectiva diferencialista. As trajetórias do feminismo e dos grupos raciais demonstrariam tal possibilidade. ${ }^{5}$ Além de se afastar dos perigos do "diferencialismo de direita", antagônicos à idéia de igualdade, esse "novo universalismo" possibilitaria o convívio entre o respeito às diferenças e o respeito à individualidade.

Outra formulação que dá conta dos riscos do "diferencialismo de esquerda" e propõe uma saída para a tensão entre igualdade e diferença pode ser encontrada na tipologia proposta por Sérgio Paulo Rouanet. ${ }^{7}$ Como categoria geral, o diferencialismo postula uma distinção de natureza entre Ego e Alter, que não existe para o igualitarismo. Diferencialismo e igualitarismo se dividem em dois, conforme suas intenções políticas: dominação ou liberdade.

O diferencialismo pode ser repressivo ou crítico. No diferencialismo repressivo, motivado pela dominação, o outro é um intruso investido das características de uma estranheza radical; a diferença é irremovível e ameaçadora, e seus resultados podem ser constatados no imperialismo, no colonialismo, no racismo e no sexismo, bem como nas formas modernas de totalitarismo e fascismo. Por sua vez, o diferencialismo crítico, ao buscar emancipação e liberdade, parte da percepção do Alter como diferente. A afirmação da diferença pelo dominado, portanto, é uma via para a conquista de autonomia, podendo ser exemplificada por certos movimentos sociais. Na prática, todavia, o diferencialismo crítico corre o risco de resultar numa glorificação do gueto e na instauração de um apartheid de esquerda, incrementando inclusive práticas do diferencialismo repressivo, como referido acima no que tange ao diferencialismo de direita.

\footnotetext{
${ }^{5}$ A produção teórica feminista poderia, conforme Pierucci, ser assim resumida: "(1) da igualdade acima das diferenças passa-se à diferença de gênero; (2) da diferença de gênero, que representa a diferença feminina no singular em relação ao mundo masculino também no singular, (3) chega-se a uma nova descoberta empírica, a das diferenças 'entre as mulheres', as diferenças "de dentro" (Pierucci, 1999: 149). Em resumo, da igualdade (1) à diferença e (2) desta às diferenças. A questão racial apresenta caminho similar: de um modelo 'uni-racial', 'colorblindness' (1) a um modelo bi-racial, centralizado na negritude (2) e deste ao multiculturalismo (: 138-40).

${ }^{6}$ Richard Rorty chega a uma conclusão parecida, ao relativizar a importância dos debates em torno do binômio identidade/diferença. Após localizar na crítica feita por Nietzsche, Heidegger e Derrida à metafísica grega o surgimento contemporâneo desses temas, sustenta que as "políticas de identidade" simplesmente conferem concretude contemporânea à utopia igualitária liberal, cujo conteúdo apontaria para o maior espaço possível ao pluralismo, por meio da exigência de um acordo entre os grupos acerca da maior abertura possível das instituições (Rorty, 1999: 232-9).

7 Nos parágrafos que se seguem, reproduzo algumas sentenças e expressões de Rouanet (1994).
} 
O igualitarismo, por sua vez, pode ser abstrato ou concreto. Em sua versão abstrata, a igualdade de todos acima de qualquer diferença se mostra vazia, impedindo inclusive que os seres humanos reais e concretos lutem por uma equalização efetiva, ou seja, que transformem a igualdade de direito em igualdade de fato. Isso, aliás, corresponde a um falso igualitarismo, uma vez que o Outro só será igual quando se despojar de tudo o que constitui sua especificidade. Ademais, implica a anulação do Alter e a desnecessidade de contato e comunicação, pois o define como igual ao Ego.

A melhor alternativa, portanto, é o igualitarismo concreto. Ao mesmo tempo que se distancia radicalmente do diferencialismo repressivo, ele parte da igualdade fundamental de todos e tem consciência das diferenças reais, sabendo que só valendo-se delas um projeto de emancipação que transcenda a retórica será viável. Reconhecer a diferença sem canonizá-la, admitir o conceito de identidade sem torná-la fixa e fechada pela reificação do outro, essa é a estratégia para lidar, de modo emancipador, com a dialética da alteridade.

3 PROTEGER DISCRIMINANDO OU DISCRIMINAR PROTEGENDO?

Reconhecimento e distribuição, universalismo e particularismo, e direito à igualdade e direito à diferença são categorias que apontam para o desafio da reflexão e da prática com vistas à superação da discriminação e da desigualdade. Todas, da mesma forma, levam à questão de saber qual é a resposta jurídica e política mais adequada para promover a igualdade e o combate à discriminação.

Em termos de políticas públicas e formulações jurídicas, esses pares conceituais alertam para o chamado "dilema da diferença", que pode ser expresso em três versões:: 1) a diferença pode ser recriada ao ser registrada ou ignorada; 2) a ambigüidade da neutralidade; e 3) a tomada de decisões com base em critérios formais, rígidos e universais, ou a abertura a decisões individualizadas, com maior grau de discricionariedade.

Como dito, trata-se de três versões do mesmo fenômeno: quando se destaca a diferença para a proteção contra discriminação, pode-se engendrar mais diferença e preconceito ${ }^{9}$ (primeira versão); permanecer inerte diante de uma realidade de discriminação, sob o argumento de neutralidade, pode, no entanto, conduzir à cumplicidade com tal realidade discriminatória (segunda versão). Diante desse quadro, exsurge a terceira versão do dilema, cujas alternativas trazem consigo os riscos ínsitos nas duas primeiras: confiar em regras universais, formais e rígidas, a fim de evitar mais diferenciação e preconceito, quedando-se neutro, ou permitir margens cada vez maiores de liberdade de decisão diante de cada caso, com o intuito de afastar o perigo da cumplicidade com a discriminação, mas correndo o risco de decidir injustamente e alimentar o dilema em sua primeira versão.

\footnotetext{
${ }^{8}$ Utilizo, neste ponto, a elaboração desenvolvida em Minow (1990). Ver também Minow (1987:10-ss).

${ }^{9}$ Esse fenômeno é demonstrado de modo claro por Janet Halley (1995) e Dan Danielsen (1995).
} 
Diante deste dilema, como desenvolver e aplicar a legislação antidiscriminação? Conforme Martha Minow (1987), o primeiro passo é atentar que: 1) a diferença não é algo intrínseco, mas sempre relacional, socialmente construído; ${ }^{10}$ 2) sempre existe um paradigma pressuposto quando se qualifica algo ou alguém como "diferente", sendo necessário, portanto, explicitá-lo e discuti-lo; 3) na produção da diferença, tal paradigma representa apenas um dos pontos de vista possíveis, devendo-se considerar outros; e 4) via de regra, toma-se o status quo como algo natural, espontâneo e legítimo, donde a corriqueira confusão entre inação e neutralidade, e medidas corretivas e favorecimento ou privilégio.

Tendo isso presente, o segundo passo é avaliar as medidas suspeitas de discriminação, levando em consideração o maior número possível de perspectivas e relativizando os paradigmas assentes, para que se apresente um número maior de alternativas. Desse procedimento não brotam, por si só, soluções acabadas, mas ele não apenas permite que algumas discriminações antes despercebidas se tornem visíveis, como também alerta para preconceitos contra "os diferentes" até então não questionados.

O passo seguinte é levar a sério, de modo respeitoso, ${ }^{11}$ as diversas perspectivas (: 75-ss). Tudo, é claro, sem resvalar da aceitação da diversidade para uma atitude de "mútua indiferença", dominada pela passividade e manifesta na omissão, no refúgio em modelos e categorias cristalizadas ou na simples negação da realidade discriminatória. Esse procedimento, considerado por inteiro, torna a dinâmica do direito da antidiscriminação mais apta a responder, nos limites humanos, às intrincadas questões sobre igualdade e discriminação, e também a evitar, na medida do possível, efeitos negativos do "dilema da diferença".

\section{REFERÊNCIAS}

DANIELSEN, Dan (1995) "Identity Strategies: representing pregnancy and homosexuality". Em: danielsen, dan \& engle, Karen (eds.). After identity. New York: Routledge.

FRASER, Nancy (1997) Justice Interruptus: critical reflections on the 'postsocialist' condition. New York: Routledge. (2001) "Social Justice in knowledge Society: redistribution, recognition, and participation". Disponível em

www.wissensgesellschaft.org-themen-orienterung-socialjustice.pdf. Acesso em 8 fev. 2003.

\footnotetext{
${ }^{10}$ Exemplos disso são as questões de deficiência física e de raça. A determinação da condição subjetiva do indivíduo depende de uma série de considerações e varia conforme a qualidade das relações dos envolvidos. Para alguns, a gestação configuraria, em certas circunstâncias, uma condição de deficiência, ainda que temporária. A condição da população soropositiva para o vírus HIV, inicialmente concebida, de modo invariável, como inabilitação generalizada, é cada vez mais discutida e contestada. Na questão racial, por exemplo, a Suprema Corte constatou a insuficiência de fontes "científicas" para acionar ou não o critério de raça, previsto em leis contrárias à discriminação, em casos envolvendo judeus e árabes (Saint Francis College v. Al-Khazraji (1987) e Shaare Tefila Congregation v. Cobb (1987).

${ }^{11}$ A utilização desse termo não é gratuita: respeito implica muito mais que "simpatia" e "grandeza ou abertura de espírito" com os diferentes. Requer considerar o outro em pé de igualdade.
} 
HALLEY, Janet (1995) "The Politics of the Closet: legal articulation of sexual orientation identity". Em: DANIELSEN, Dan; ENGLE, Karen (eds.). After identity. New York: Routledge.

KOPPELMAN, Andrew (1996) Antidiscrimination, law and social equality. New Haven: Yale University Press.

LOPES, José Reinaldo de Lima (2003) "O Direito ao Reconhecimento para Gays e Lésbicas". Em: GOLIN, Célio; POCAHY, Fernando A.; RIOS, Roger Raupp (orgs.) A Justiça e os Direitos de Gays e Lésbicas - jurisprudência comentada. Porto Alegre: Nuances/Sulina.

MINOW, Martha (1987) "Foreword [to the Supreme Court 1986 term]: Justice Engendered", Harvard Law Review, vol. 101, 1987-8.

(1990) Making all the Difference: inclusion, exclusion, and American law. Ithaca: Cornell University Press.

PIERUCCl, Antônio Flávio (1999) As ciladas da diferença. São Paulo: Ed. 34.

RIOS, Roger Raupp (2008) Direito da antidiscriminação: discriminação direta, indireta e suas subdivisões. Porto Alegre: Editora Livraria do Advogado.

RORTY, Richard (1999) Philosophy and social hope. London: Penguin Books.

ROUANET, Sérgio Paulo (1994) "Identidade e diferença: uma tipologia", Revista Sociedade e Estado, $\mathrm{n}^{\circ} 1$ e 2, Brasília.

STEIN, Edward (1999) The mismeasure of desire: the science, theory, and ethics of sexual orientation. New York: Oxford University.

TAYLOR, Charles (1994) "The Politics of Recognition". Em: GUTMANN, Amy (ed.) Multiculturalism: examining the politics of recognition. Princeton: Princeton University Press. 